\title{
Efeito do estresse térmico calórico agudo e crônico sobre a qualidade oocitária de bovinos de raças adaptadas
}

\author{
[Effect of acute and chronic caloric heat stress on oocyte quality of adapted breeds cattle] \\ A.L.L. Fialho ${ }^{1}$, M.B.Souza-Cáceres ${ }^{2}$, W.A.L. Silva ${ }^{3}$, E.D.S. Arruda ${ }^{4}$, H. Kischel ${ }^{4}$, \\ M.G.C. Ribeiro-Ferreira ${ }^{1}$, C.F. Medeiros ${ }^{4}$, J.R. Silva ${ }^{4}$, M.V.M. Oliveira ${ }^{5}$, \\ A.L.J. Ferraz ${ }^{5}$, F.A. Melo-Sterza ${ }^{5,6^{*}}$ \\ ${ }^{1}$ Aluno de pós-graduação - Universidade Estadual de Mato Grosso do Sul - Aquidauana, MS \\ ${ }^{2}$ Aluno de pós-graduação - Universidade Estadual de Londrina - Londrina, PR \\ ${ }^{3}$ Aluno de pós-graduação - Universidade Federal de Mato Grosso do Sul - Campo Grande, MS \\ ${ }^{4}$ Aluno de graduação - Universidade Estadual de Mato Grosso do Sul - Aquidauana, MS \\ ${ }^{5}$ Universidade Estadual de Mato Grosso do Sul - Aquidauana, \\ ${ }^{6}$ Universidade Federal de Mato Grosso do Sul, MS
}

\begin{abstract}
RESUMO
Nos trópicos, o uso de raças adaptadas tem sido uma estratégia para minimizar o efeito do estresse térmico calórico (ETC). No entanto, faltam informações que quantifiquem o estresse e o seu efeito sobre a reprodução dessas raças. $\mathrm{O}$ objetivo deste estudo foi avaliar a qualidade do oócito recuperado e alguns parâmetros fisiológicos indicadores de ETC em bovinos de raças adaptadas. Animais Bos taurus x Bos indicus (n=6) e Bos taurus (raça Pantaneira; $n=12$ ), localizados na região de transição entre o Cerrado e o Pantanal brasileiro, foram submetidos à aspiração folicular guiada por ultrassonografia (OPU) em diferentes condições climáticas. Foram realizadas oito sessões de OPU, com intervalo mínimo de sete dias e máximo de 54 dias entre as coletas. Para caracterização climática, foi realizado o cálculo do índice de temperatura e umidade (ITU). Foram quantificados os ITUs do dia da OPU, sete dias antes e 60 dias antes de cada sessão. Os parâmetros fisiológicos e a viabilidade oocitária de fêmeas das raças Girolando e Pantaneira não foram afetados negativamente por ITUs entre 72 e 78. O ETC crônico (60 dias) parece afetar a viabilidade oocitária de doadoras na raça Pantaneira quando ITU é superior a 75.
\end{abstract}

Palavras-chave: ambiente, bovinos, ITU, oócito

\begin{abstract}
In tropical regions, the use of adapted breeds has been a strategy to minimize the effect of heat stress (HS) in cattle. However, information quantifying stress and its effect on reproduction of these breeds is lacking. The aim of this study was to evaluate the quality of the recovered oocyte and some physiological parameters that indicate HS in adapted breed. Bos taurus x Bos indicus $(n=6)$ and Pantaneira $(n=12)$ cows, located in the transition region between Cerrado and Brazilian Pantanal, underwent follicular aspiration guided by ultrasound (OPU) in different weather conditions. Eight sessions of OPU were carried out, with a minimum interval of 7 days and maximum 54 days between sessions. For weather characterization, the temperature and humidity index (THI) was calculated. THI of the day of OPU, 7 days before and 60 days before each session were calculated. The physiological parameters and oocyte viability of Girolando and Pantaneira cows were not negatively influenced under ITU between 72 and 78. The chronic HS (60 days)may affect the oocyte viability of Pantaneira donors when ITU is over 75.
\end{abstract}

Keywords: bovine, environment, THI, oocytes

Recebido em 21 de outubro de 2016

Aceito em 10 de fevereiro de 2017

* Autor para correspondência (corresponding author)

E-mail: fabiana.sterza@uems.br 


\section{INTRODUÇÃO}

A maior parte do rebanho bovino brasileiro encontra-se em região tropical, com temperaturas médias acima da zona de termoneutralidade (Pires e Campos, 2008), onde os animais permanecem longos períodos sob estresse térmico calórico (ETC). Independentemente da origem genética, o estresse térmico por calor prejudica a homeostase, o que leva a alterações endócrinas e a efeitos negativos sobre eventos reprodutivos na fêmea bovina (Macedo et al., 2014). O ETC provoca alteração do desenvolvimento folicular, diminuição ou atraso da expressão do comportamento do estro, comprometimento da competência oocitária (Gendelman et al., 2010) e pode também atrasar ou mesmo inibir o desenvolvimento embrionário (Ferreira et al., 2011). O desenvolvimento embrionário é prejudicado quando as fêmeas sofrem de estresse por calor no dia da IA até sete dias após esse procedimento, o que acarreta menor viabilidade embrionária (Macedo et al., 2014).

As regiões tropicais têm problemas a serem estudados e superados com pesquisas que propiciem soluções adequadas para uma perfeita interação animal-ambiente, com vistas à maior produtividade (Faria, 1999). Assim, a utilização de animais adaptados aos trópicos é indicada para melhorar a produtividade nessas regiões.

Os animais Pantaneiros possuem ácido desoxirribonucleico (DNA) mitocondrial essencialmente taurino, herdado de seus ancestrais ibéricos (Issa et al., 2006), sendo atualmente considerada uma raça Bos taurus taurus genuinamente brasileira e localmente adaptada ao bioma do Pantanal (Rufino Júnior et al., 2014). Por outro lado, o Girolando é uma raça sintética, resultante do cruzamento entre bovinos Holandeses (Bos taurus taurus) com animais da raça Gir (Bos taurus indicus), cujo objetivo é buscar a complementaridade entre essas raças, de modo a aliar a produtividade das vacas Holandesas à maior resistência do gado Gir às condições climáticas dos trópicos.

A produção in vitro de embriões pode ser considerada uma alternativa para manejar os efeitos do ETC, pois etapas essenciais da reprodução, tais como a maturação oocitária e o desenvolvimento inicial dos embriões, ocorrem em ambiente controlado. No entanto, não está claro o efeito do ETC sobre a foliculogênese e a oogênese, bem como o seu impacto sobre a qualidade dos complexos cumulus-oócitos (COCs) obtidos por OPU. Quedas na qualidade dos COCs têm sido associadas a alterações das condições fisiológicas dos animais (Bilby et al., 2014), fato que estimula o estudo mais apurado dessa questão.

Armstrong (1994) definiu níveis de estresse (ameno a severo) para bovinos, de acordo com os valores de ITU. No entanto, a aplicabilidade desses valores para bovinos de raças adaptadas aos trópicos e a influência do estresse agudo e crônico sobre parâmetros reprodutivos ainda precisam ser avaliados.

O objetivo do presente estudo foi avaliar a influência do ETC agudo e crônico sobre os parâmetros físiológicos e o número e a viabilidade dos COCs aspirados de fêmeas das raças Pantaneira e Girolando.

\section{MATERIAL E MÉTODOS}

Animais das raças mestiças Bos taurus x Bos indicus (Girolando livro aberto; $\mathrm{n}=6$ ) e Pantaneira $(\mathrm{n}=12)$ foram selecionados de acordo com suas características clínico-reprodutivas. As doadoras eram vacinadas contra doenças infecciosas e reprodutivas (vacinação realizada pelo menos 60 dias antes da primeira $\mathrm{OPU}$ ), não gestantes, com idade média de 48 meses e escore corporal entre 3 e 3.5 (escala de 1 a 5).

O experimento foi realizado na Universidade Estadual de Mato Grosso do Sul, situada em lat. $20^{\circ} 30^{\prime} \mathrm{S}$, long. $55^{\circ} 50^{\prime} \mathrm{W}$. Os animais estavam em regime de pastejo rotacionado, cultivado com capim-tanzânia (Panicum maximum), com suplementação mineral e água ad libitum.

Foram realizadas oito sessões de OPU, com intervalo mínimo de sete dias e máximo de 54 dias entre as coletas, durante os meses de maio a novembro de 2014. Cada animal foi submetido a, no mínimo, uma sessão e a, no máximo, oito sessões de OPU. Todos os procedimentos de OPU foram realizados com o mesmo número de doadoras para as duas raças, sendo no mínimo seis e no máximo 10 animais por coleta. Todos os procedimentos realizados foram aprovados pela Comissão de Ética no Uso de Animais, por meio do Protocolo Ceua/UEMS 013/2013. 
Para redução dos movimentos peristálticos e menor desconforto do animal, foram injetados $5 \mathrm{~mL}$ de uma combinação de lidocaína $2 \%$ e acepromazina $1 \%$ no espaço epidural. Para a aspiração dos folículos, foram utilizadas agulhas hipodérmicas descartáveis $20 \mathrm{G}(50 \mathrm{~mm} \times 9 \mathrm{~mm}$; Terumo ${ }^{\circledR}$, Bio Brasil) e mangueira de silicone com $2 \mathrm{~mm}$ de diâmetro interno e $80 \mathrm{~cm}$ de comprimento. A pressão de vácuo foi de $80 \mathrm{~mm}$ de $\mathrm{Hg}$, mantida com uma bomba de aspiração (Aquila PRO®, Pie Medical, acoplado a transdutor microconvexo $8 \mathrm{MHZ}$ e bomba à vácuo $\mathrm{BV}-003 \mathrm{D}$ WTA). O meio de aspiração era constituído por DPBS acrescido de 20.000UI/L de heparina sódica, mantido a $30^{\circ} \mathrm{C}$ durante a aspiração. Os COCs recuperados foram rastreados e classificados imediatamente após a OPU. Foram considerados como viáveis os COCs com uma ou mais camadas de células do cumulus compactas e citoplasma homogêneo.

Antes da realização de cada OPU, foi aferida a temperatura retal, com termômetro digital de uso veterinário. A frequência respiratória de cada animal manejado era contada de acordo com os movimentos do flanco em movimentos por minuto. Tais procedimentos foram realizados em todos os animais, em todas as coletas.

Para o cálculo do índice de temperatura e umidade (ITU), foram utilizados os dados de temperatura do ar (T) e umidade relativa (UR), provindos da estação meteorológica da Universidade Estadual de Mato Grosso do Sul (UEMS). O cálculo do ITU foi feito de acordo com Thom (1959), sendo: ITU $=(0,8 \mathrm{x}$ $\mathrm{T}+(\mathrm{UR}(\%) / 100) \times(\mathrm{T}-14,4)+46,4)$, em que: $\mathrm{T}=$ temperatura $\left({ }^{\circ} \mathrm{C}\right)$ e UR $=$ umidade relativa do ar. Os valores obtidos a partir da equação foram classificados no modelo definido por Armstrong (1994) em ameno ou brando (72 a 78), moderado (79 a 88) e severo (89 a 98). ITU abaixo de 72 caracterizaria um ambiente sem estresse por calor. Foram calculados ITU de sete e 60 dias antes da OPU, e no dia da OPU, com o objetivo de caracterizar o ETC crônico (60 dias) e agudo (sete a zero dias). O ITU foi calculado de hora em hora, durante todos os dias do período experimental. Foram, assim, considerados o ITU da manhã (cálculo médio entre oito e 11 horas da manhã), da tarde (cálculo médio entre às 13 e 16 horas) e do dia todo (cáculo da média do ITU de cada hora das 24 horas do dia).
Para a análise estatística, os dados foram submetidos à regressão linear e à análise de variância pelo programa $\mathrm{R}$ (versão 3.3.1). Quando encontradas diferenças, as médias foram comparadas pelo teste de Tukey, com 5\% de probabilidade.

\section{RESULTADOS E DISCUSSÃO}

A região de transição entre o Cerrado e o Pantanal brasileiro é conhecida pelas altas temperaturas ambientais registradas em grande parte do ano. O perfil climático do período experimental demonstrou que apenas nos meses de maio, junho e julho as temperaturas do dia foram inferiores a $25^{\circ} \mathrm{C}$. A UR foi, em geral, alta, mas apresentou grande variação nos meses mais quentes do período (Fig. 1). Segundo Barros et al. (2010), a alta umidade do ar, combinada com elevadas temperaturas, acarreta mudanças no comportamento fisiológico do animal, o que promove maior gasto de energia para manutenção de sua homeostase. Nesses casos, ocorre redução dos índices produtivos e reprodutivos do animal.

A grande variação climática que ocorre ao longo do dia pode subestimar o ETC ao qual os animais são submetidos. Navarini et al. (2009), Fialho (2015) e Kischel (2016) relataram esse fato e concluíram sobre a baixa eficiência da utilização do ITU médio do dia para determinar o ETC. No presente estudo, o ETC da manhã e da tarde foram significativamente superiores ao ITU do dia todo, e não foi verificada diferença estatística entre o ITU do período da manhã e o da tarde (Fig. 2).

Na Fig. 2, pode ser observada a variação do ITU 60 e sete dias antes da OPU e no dia da OPU nas oito sessões de OPU.

Considerando-se o ITU médio do dia da OPU, seria possível afirmar que, nas coletas 1, 2, 4 e 5, os animais encontravam-se em conforto térmico, no entanto o mesmo fato não foi observado para os ITUs médios do dia da OPU nos períodos da manhã e da tarde, o que confirma a necessidade de considerar os horários mais quentes do dia para determinar o ETC. Considerando-se o ITU dos sete dias anteriores a cada OPU e do dia da OPU, somente em uma das coletas o ITU da tarde foi inferior a 72. Observou-se, no entanto, variação importante desse índice entre as sessões de aspiração folicular. 


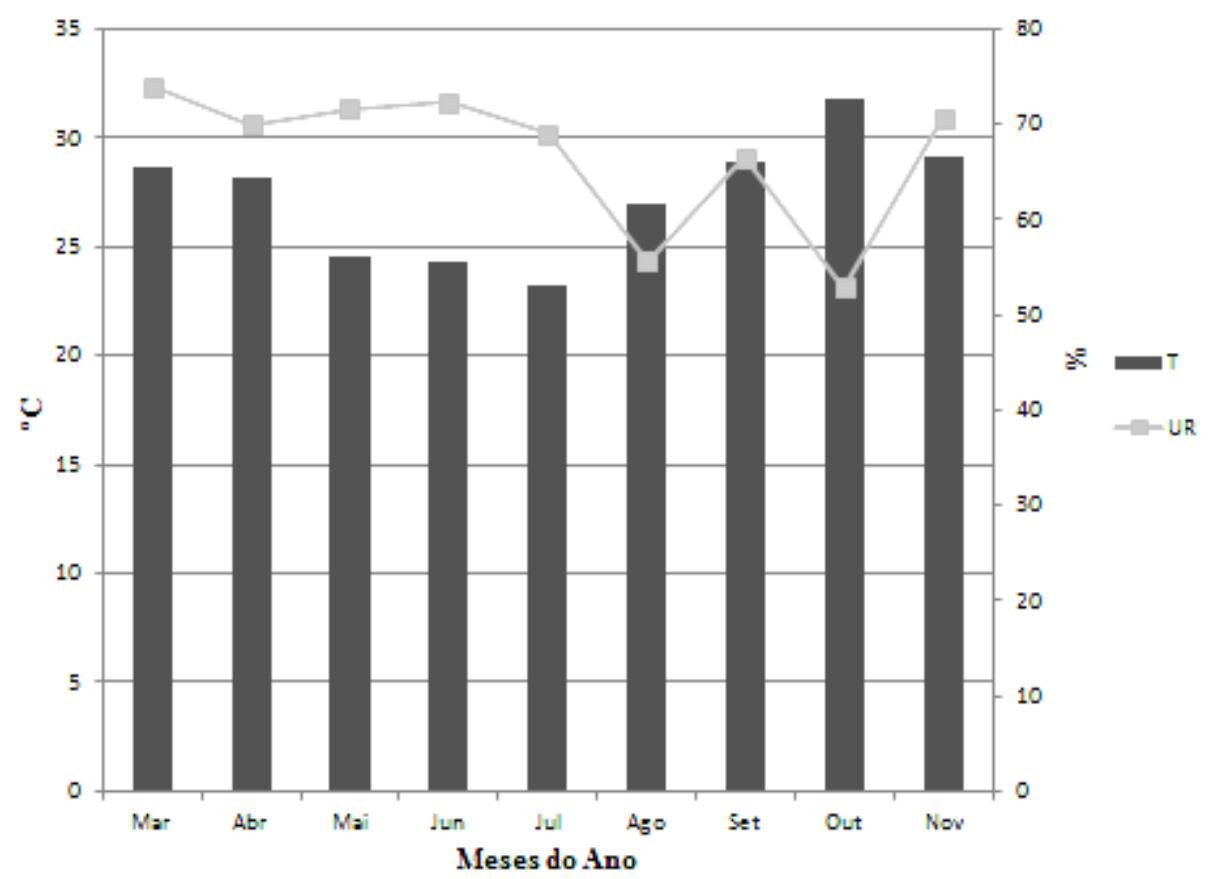

Figura 1. Perfil climático do período experimental - março a novembro/2014. Os dados de temperatura $\left(\mathrm{T}\right.$, em ${ }^{\circ} \mathrm{C}$ ) e umidade relativa do ar (UR, em \%) foram obtidos da estação metereológica da UEMS. Foram considerados nesse gráfico os períodos das oito às 11 horas e das 13 às 16 horas.
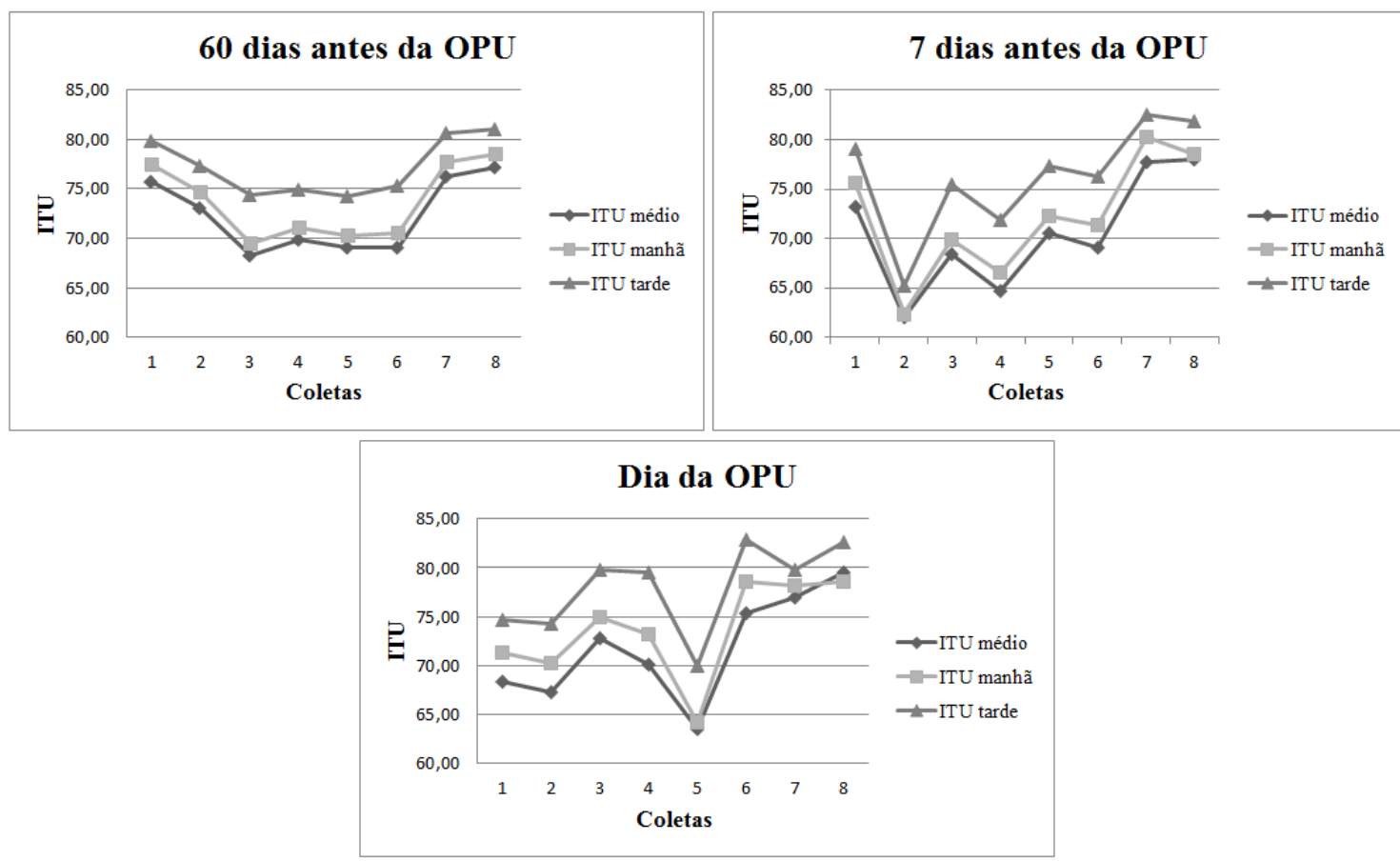

Figura 2. Índice de temperatura e umidade (ITU) 60 e sete dias antes da OPU e no dia da OPU de vacas das raças Pantaneira e Girolando. 
A grande variação climática observada demonstra que a caracterização do conforto térmico baseada apenas nas estações do ano também é muito frágil (coleta 1 e 2 : maio; coleta 3 e 4: julho; coleta 5 e 6: agosto; coleta 7: outubro; coleta 8: novembro).

Ao observar o ITU médio dos 60 dias anteriores à $\mathrm{OPU}$, constata-se que, nas sessões de $\mathrm{OPU} 1,2$, 7 e 8 , os animais estavam em estresse crônico, ou seja, foram submetidos a ITUs superiores a 72, em média, durante 60 dias. Quando apenas o ITU da tarde é considerado, observa-se que, em todas as sessões de aspiração, o ITU estava acima de 72 .

A escolha de raças mais adaptadas às regiões de clima quente tem sido uma alternativa para manejar os efeitos de ETC sobre a produção animal. As raças Girolando e Pantaneira se enquadram nessa categoria.

Não foi observada diferença estatística da temperatura retal, frequência respiratória e frequência cardíaca entre as sessões de OPU, o que indica que, provavelmente, animais das raças estudadas não sofrem de ETC em ITUs entre 72 e 78 (ITU máximo observado no momento da OPU). Os dados apresentados na Tab. 1 são oriundos das médias de todas as coletas e aferições no período experimental, independentemente do ITU, sendo considerado apenas o efeito da raça, já que nenhum efeito do ETC agudo foi observado sobre os parâmetros avaliados.

Tabela 1. Parâmetros fisiológicos e qualidade de complexos oócitos - cumulus (COCs) obtidos por aspiração folicular guiada por ultrassonografia das raças Girolando e Pantaneira

\begin{tabular}{ccccc}
\hline Raça & Temperatura retal & $\begin{array}{l}\text { Frequência } \\
\text { respiratória }\end{array}$ & Total de COCs & COCs viáveis \\
\hline Girolando & $38,31 \pm 0,07^{\mathrm{a}}$ & $32,1 \pm 1,4^{\mathrm{a}}$ & $6,7 \pm 0,8^{\mathrm{a}}$ & $3,1 \pm 0,4^{\mathrm{a}}$ \\
Pantaneira & $38,64 \pm 0,07^{\mathrm{b}}$ & $28,6 \pm 1,4^{\mathrm{a}}$ & $7,4 \pm 0,8^{\mathrm{a}}$ & $3,7 \pm 0,4^{\mathrm{a}}$ \\
\hline
\end{tabular}

*Médias seguidas de letras distintas nas colunas diferem pelo teste de Tukey $(\mathrm{P}<0,05)$.

A temperatura retal é usada, frequentemente, como parâmetro de definição de adaptação fisiológica ao ambiente quente, pois seu aumento indica que os mecanismos de liberação de calor tornaram-se insuficientes para manter a homeotermia (DuPreez, 2000). Apesar de ter sido constatada diferença na TR entre as raças, essa distinção não superou a faixa de normalidade para a espécie, em nenhum dos dias em que a OPU foi realizada, o que confirma que os animais conseguiram manter a homeotermia em ITUs de até 78. Em estudos anteriores, foi relatado que bovinos que estão em situação de ETC apresentam TR com valores acima de $39^{\circ} \mathrm{C}$ (Pires e Campos, 2008; Vasconcelos e Demétrio, 2011), situação não observada neste estudo.

O fato de os parâmetros fisiológicos (TR e FR) e reprodutivos (viabilidade de COCs) da raça Pantaneira (taurina) serem semelhantes aos animais Girolando, uma raça mestiça (Bos taurus $x$ Bos indicus) e moldada sinteticamente para as condições tropicais, confirma a adaptação dos animais Pantaneiros às condições climáticas da região do Alto Pantanal Sul-Matogrossense, já relatada anteriormente (Marques Jr et al., 2012).

A frequência respiratória é, em geral, o primeiro parâmetro fisiológico a ser alterado em situações de estresse pelo calor, atuando como alternativa de dissipação de calor e controle da temperatura corporal (Costa et al., 2015). Azevedo et al. (2005), ao avaliarem vacas mestiças, observaram que a frequência respiratória evidenciou ser um indicador de estresse térmico melhor que a temperatura retal, assim como no presente experimento. Neste ensaio, a frequência respiratória em doadoras da raça Girolando foi aumentando linearmente à medida que houve aumento de ITU, fato não observado na raça Pantaneira (Fig. 3 ).

De acordo com Moraes (2010), quanto menor a FR mais adaptado é o animal ao ETC. Apesar de as doadoras da raça Girolando demonstrarem a referida variação de $\mathrm{FR}$, até ITU 79,5, a FR manteve-se dentro da normalidade. 


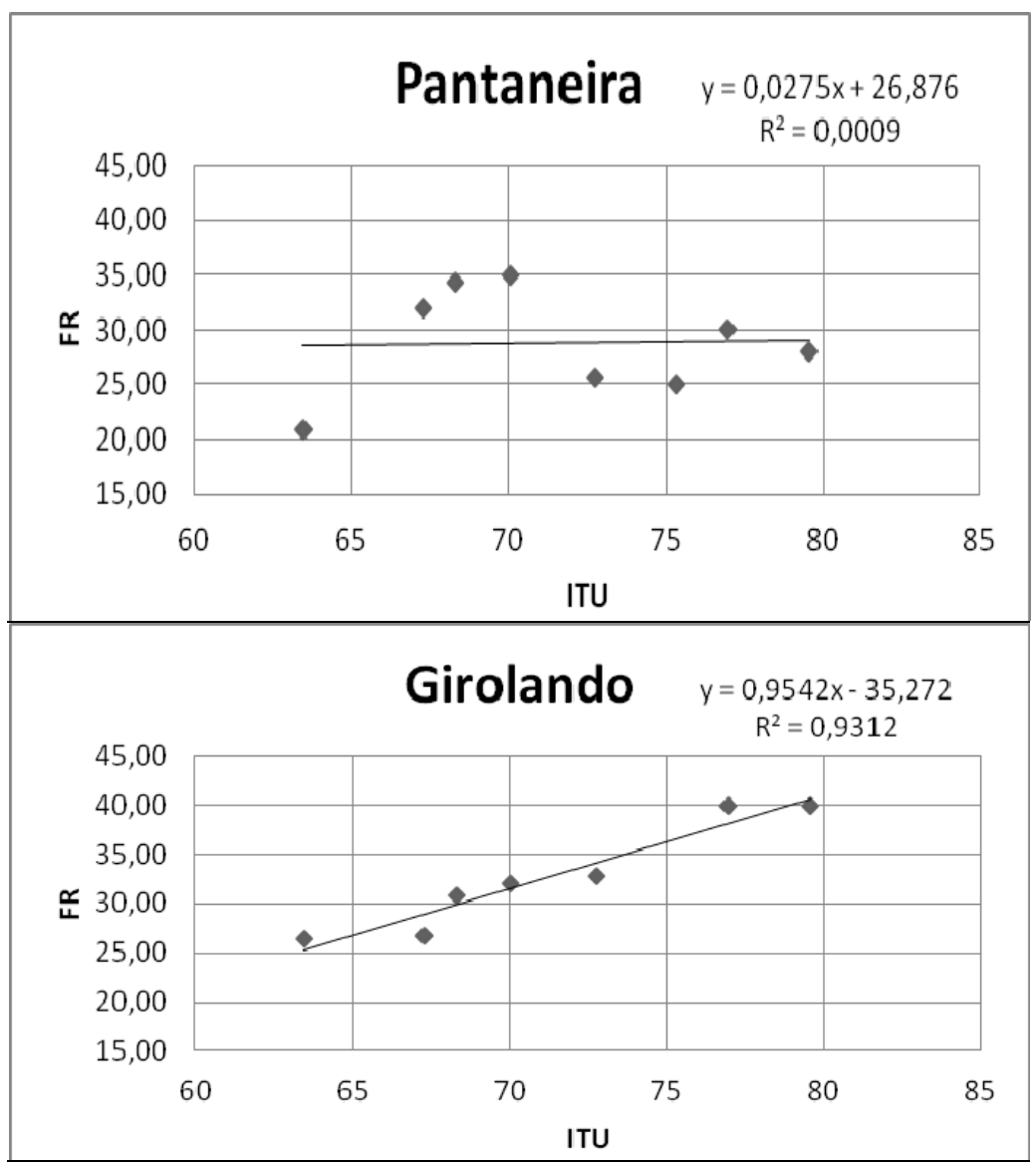

Figura 3. Análise de regressão da frequência respiratória $(\mathrm{FR})$ de animais da raça Girolando $(\mathrm{P}=0,02841)$ e Pantaneira $(\mathrm{P}=0,1278)$ em relação ao ITU do período em que foram realizadas as OPUs.

Avaliações empíricas normalmente associam as condições climáticas aos resultados de OPU e da múltipla ovulação e transferência de embriões. No entanto, são escassas as informações científicas a esse respeito. Considerando-se que um folículo antral de $0,13 \mathrm{~mm}$ de diâmetro leva aproximadamente 42 dias, ou seja, aproximadamente dois ciclos estrais para atingir o tamanho pré-ovulatório em uma vaca (Lussier et al., 1987), acredita-se que o ETC crônico possa impactar, de maneira significativa, sobre a eficiência reprodutiva.

Chebel (2014) relatou que o estresse crônico ou múltiplos estresses agudos podem acarretar alterações hormonais, o que prejudica a qualidade do oócito e o desenvolvimento inicial embrionário. Roth et al. (2001) relataram que folículos que se desenvolvem sobre condições de estresse térmico possuem uma deficiência na esteroidogênese das células da teca e granulosa, e, como consequência, ocorre uma redução nas concentrações de estradiol no fluido folicular. Essa redução pode afetar a secreção de gonadotrofinas que estejam envolvidas na aquisição de competência meiótica dos oócitos.

O número de COCs obtidos neste experimento foi semelhante entre as raças nas condições do Cerrado-Pantanal. Todavia, o número de COCs totais e viáveis obtidos da raça Girolando, no presente experimento, foram inferiores aos verificados por Pontes et al. (2010), que obtiveram média de 15 COCs viáveis/doadora. Vale ressaltar que a grande variação individual de COCs aspirados da raça Girolando já havia sido relatada (Prado et al., 2007) e está relacionada à idade, à categoria, às condições ambientais, ao status nutricional e até mesmo àquelas inerentes à genética do próprio animal. Sobre a raça Pantaneira, ainda não existem relatos a esse respeito. 
Como esperado, não foi observada interferência do ITU sobre a viabilidade oocitária, quando avaliados os dados de sete dias anteriores à OPU e no dia da OPU. Porém, quando se avaliou o estresse crônico (60 dias antes da OPU), pôde-se ver uma evidente queda na qualidade dos COCs das doadoras da raça Pantaneira à medida que houve o aumento do ITU (Fig. 4). As doadoras da raça Pantaneira também produziram mais COCs viáveis em períodos sem ETC. Esses resultados corroboram os de Torres-Júnior et al. (2008), que observaram alteração da dinâmica folicular e redução da competência oocitária até 119 dias depois do ETC de 28 dias induzido em vacas Gir, em câmara climática.

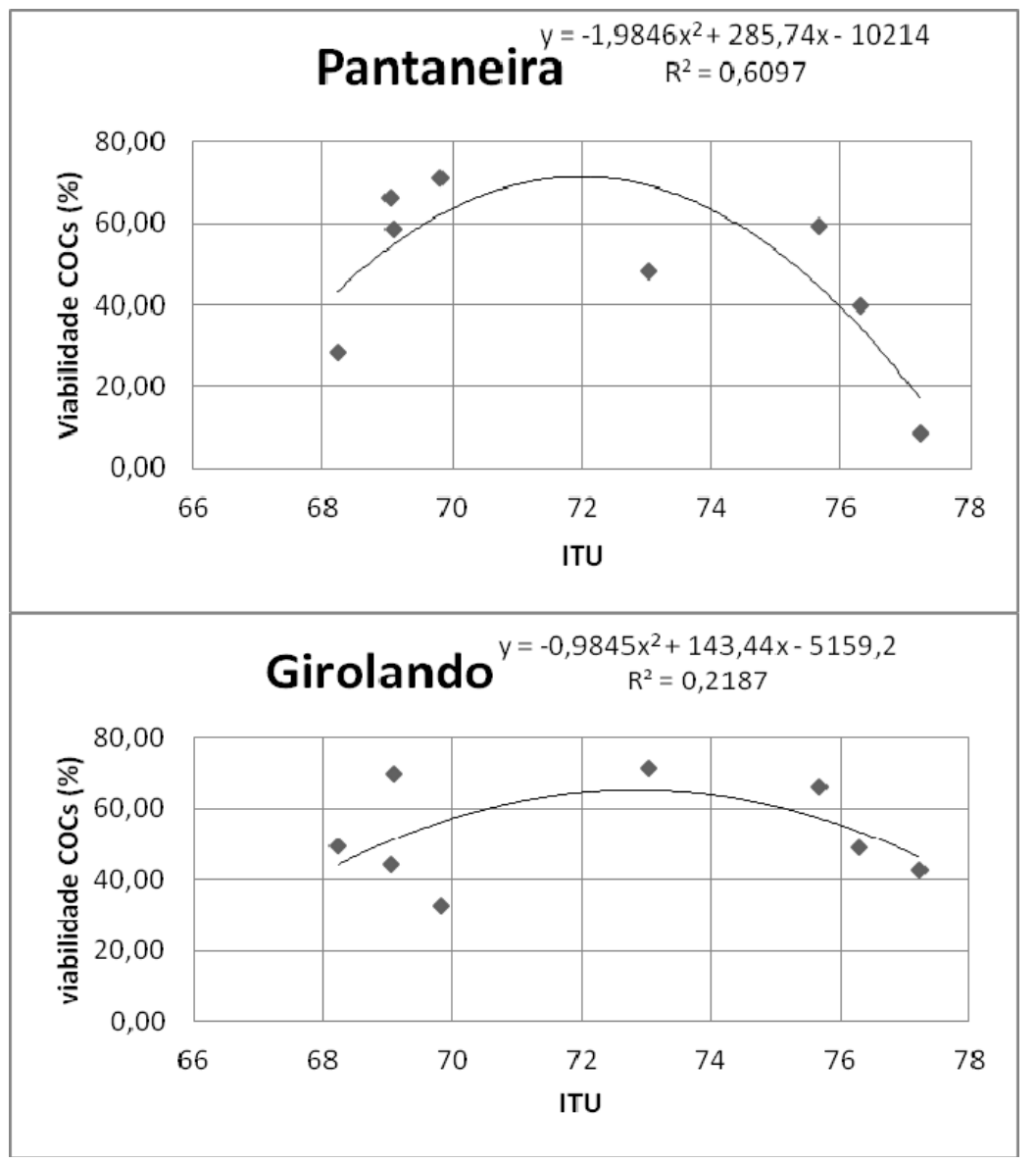

Figura 4. Análise de regressão da viabilidade de COCs de doadoras da raça Pantaneira $(\mathrm{P}=0,01405)$ e Girolando $(\mathrm{P}=0,8383)$ em relação aos valores de ITU, dos 60 dias antes da OPU.

O fato de a viabilidade oocitária das fêmeas Girolando não ter sofrido influência significativa de ETC crônico pode estar relacionado ao aumento da FR (observado nessa raça quando houve aumento de ITU) associado a mecanismos de regulação da temperatura do estroma ovariano (Hunter e Einer-Jensen, 2005), o que auxilia na termorregulação desses animais, de forma suficiente a não interferir na qualidade do oócito.
O valor do índice de temperatura e umidade a partir do qual vacas Holandesas iniciam o declínio na produção de leite é igual a 72 (Silva et al., 2002). Entretanto, na literatura nacional e na estrangeira, há poucas informações a respeito dos níveis críticos desse índice para vacas mestiças (Azevedo et al., 2005). Azevedo et al. (2005) relataram que a temperatura retal de animais mestiços só ultrapassou os parâmetros fisiológicos normais quando valores de ITU foram iguais a 80,77 e 75 para os animais dos 
grupos genéticos $1 / 2, \quad 3 / 4 \quad$ e $\quad 7 / 8 \quad \mathrm{HZ}$, respectivamente. A frequência respiratória só foi alterada quando os valores de ITU foram iguais a 79,77 e 76 para os animais dos grupos genéticos $1 / 2,3 / 4 \mathrm{e}^{7} / 8 \mathrm{HZ}$, respectivamente.

Os resultados obtidos neste ensaio permitem sugerir que a classificação de ETC sugerida por Armstrong (1994) não pode ser aplicada para animais de raças adaptadas aos trópicos. Neste estudo, a TR e a FR não alcançaram valores acima do padrão de referência com ITU de 77 e 79 para as vacas Girolando e Pantaneira, respectivamente. A viabilidade oocitária só esteve abaixo de $60 \%$ quando ITU foi superior a 75 nos 60 dias anteriores à OPU, para as duas raças. Dessa forma, esta pesquisa sugere que as equações de ETC já existentes para outras raças, dependem de ajustes, assim como já sugerido por Lopes (2009).

Considerando-se as alterações climáticas frequentes, assim como o fato de que os meses de dezembro, janeiro e fevereiro, classicamente de altas temperaturas e umidades, não foram avaliados neste estudo e que, mesmo assim, o efeito do estresse crônico foi observado sobre a viabilidade oocitária da raça Pantaneira, acreditase que o manejo do ambiente seja necessário para raças adaptadas para evitar o ETC crônico e garantir melhores resultados na produção in vitro de embriões.

\section{CONCLUSÃO}

Os parâmetros fisiológicos e a viabilidade oocitária de fêmeas das raças Girolando e Pantaneira não foram afetados negativamente por ITUs entre 72 e 78. O ETC agudo não interferiu na viabilidade oocitária de fêmeas das raças estudadas. O ETC crônico (60 dias) afetou a viabilidade oocitária de doadoras na raça Pantaneira quando ITU foi superior a 75.

\section{AGRADECIMENTOS}

À Fundação de Apoio ao Desenvolvimento do Ensino, Ciência e Tecnologia do Estado de Mato Grosso do Sul (Fundect/MS), ao Centro de Pesquisa do Pantanal (CPP), à Rede Pró-CentroOeste, à Coordenação de Aperfeiçoamento de Pessoal de Nível Superior (Capes) e ao Conselho Nacional de Desenvolvimento Científico e Tecnológico (CNPq), pela bolsa concedida e pelo auxílio no desenvolvimento da pesquisa.

\section{REFERÊNCIAS}

ARMSTRONG, D.V. Heat stress interaction with shade and cooling. J. Dairy Sci., v.77, p.2044-2050, 1994.

AZEVEDO, M.; PIRES, M.F.A.; SATURNINO, H.M. et al. estimativa de níveis críticos superiores do índice de temperatura e umidade para vacas leiteiras 1/2, 3/4 e 7/8Holandês-Zebu em Lactaçãolactação. Rev. Bras. Zootec., v.34, p.20002008, 2005.

BARROS, P.C.; OLIVEIRA, V.; CHAMBÓ, E.D.; SOUZA, L.C. Aspectos práticos da termorregulação em suínos. Rev. Eletron. Nutritime, v.7, p.1248-1253, 2010.

BILBY, T.R.; TATCHER, W.W.; HANSEN, P.J. Estratégias farmacológicas, nutricionais e de manejo para aumentar a fertilidade de vacas leiteiras sob estresse térmico. In: CURSO NOVOS ENFOQUES NA PRODUÇÃO E REPRODUÇÃO DE BOVINOS, 18., 2014, Uberlândia. Anais... Uberlandia, MG: [UNESP], 2014, p.59-71.

CHEBEL, R.C. Consequências do estresse sobre imunidade, metabolismo e desempenho de vacas peri-parto. In: CURSO NOVOS ENFOQUES NA PRODUÇÃO E REPRODUÇÃO DE BOVINOS, 18., 2014, Uberlândia. Anais... Uberlandia, MG: [UNESP], 2014, p.82-105.

COSTA, D.F.; SOUTO, D.V.O.; ROCHA, E.F. et al. Influência do estresse calórico na fisiologia hormonal de bovinos. Rev. Agropecu. Cient. Semiárido, v.11, p.33-38, 2015.

DUPREEZ, J.H. Parameters for the determination and evaluation of heat stress in dairy cattle in South Africa. J. Vet. Res., v.67, p.263-271, 2000.

FARIA, V.P. Produção de bovinos nos trópicos. In: FARIA, V.P.; MOURA, J.C.; PEIXOTO, A.M. Bovinocultura de corte: fundamentos da exploração racional. 3.ed. Piracicaba: FEALQ, 1999. p.23-41.

FERREIRA, R.M.; AYRES, H.; CHIARATTI, M.R. et al. The low fertility of repeat-breeder cows during summer heat stress is related to a low oocyte competence to develop into blastocysts. J. Dairy Sci., v.94, p.2383-2392, 2011

FIALHO, A.L.L. Influência das condições climáticas sobre a qualidade oocitária das raças girolando e pantaneira situadas no CerradoPantanal. 2015. 61f. Dissertação (Mestrado em Zootecnia) - Unidade Universitária Aquidauana, Universidade Estadual do Mato Grosso do Sul, Aquidauana, MS. 
GENDELMAN, M.; AROYO, A.; YAVIN, S.; ROTH, Z. Seasonal effects on gene expression, clevage timing, and developmental competence of bovine preimplantation embryos. Reproduction, v.140, p.73-82, 2010.

HUNTER, R.H.; EINER-JENSEN, N. Preovulatory temperature gradients within mammalian ovaries: a review. J. Anim. Physiol. Anim. Nutr., v.89, p.240-243, 2005.

ISSA, E.C.; JORGE, W.; SERENO, J.R.B. Cytogenetic and molecular analysis of the Pantaneiro cattle breed. Pesqui. Agropecu. Bras., v.41, p.1609-1615, 2006.

KISCHEL, H. Taxa de prenhez e paramêtros fisiológicos de vacas nelore mantidas sob diferentes condições de sombreamento natural. 2016. 22f. Trabalho de conclusão de curso (Graduação em Zootecnia) - Unidade Universitária de Aquidauana, Universidade Estadual do Mato Grosso do Sul, Aquidauana, MS.

LOPES, A.C.R. Ganho de peso e rendimento de carcaça de bovinos de corte confinados com acesso a sombra. 2009. 45f. Dissertação (Mestrado em Ciências Veterinárias) - Universidade Federal de Uberlândia, Uberlândia, MG.

LUSSIER, J.G.; MATTON, P.; DUFOUR, J.J. Growth rates of follicles in the ovary of the cow. $J$. Reprod. Fert., v.81, p.301-307, 1987.

MACEDO, G.G.; COSTA E SILVA, E.V.; PINHO, R.O. et al. $\mathrm{O}$ estresse por calor diminui a fertilidade de fêmeas bovinas por afetar o desenvolvimento oocitário e o embrionário. Rev. Bras. Reprod. Anim., v.38, p.80-85, 2014.

MARQUES JÚNIOR, H.R.; JULIANO, R.S.; ABDO, Y. Bovino pantaneiro: retrospectiva histórica e fomento à raça. Experiência da parceria entre Embrapa Pantanal, Agropecuária Preservação da Fauna e Universidade Católica Dom Bosco. Multitemas, n.42, p.71-86, 2012.

MORAES, J.B. Termorregulação e adaptabilidade climática de caprinos no semiarido piauiense. 2010. 46f. Dissertação (Mestrado em Ciência Animal) - Universidade Federal do Piauí, Teresina, PI.
NAVARINI, F.C.; KLOSOWSKI, E.S.; CAMPOS, A.T. et alet al. Conforto térmico de bovinos da raça nelore a pasto sob diferentes condições de sombreamento e a pleno sol. Eng. Agríc., v.29, p.508-517, 2009.

PIRES, M.F.A.; CAMPOS, A.T. Conforto animal para maior produção de leite. Vicosa: Centro de produções técnicas, 2008. 252p.

PONTES, J.H.F.; SILVA, K.C.F.; BASSO, A.C. et al. Large-scale in vitro embryo production and pregnancy rates from Bostaurus, Bosindicus and indicus-taurus dairy cows using sexed sperm. Theriogenology, v.74, p.1349-1355, 2010.

PRADO, F.R.A.; TONIOLLO, G.H.; OLIVEIRA, J.A. Superestimulação ovariana em vacas da raça Gir leiteiro com uso de diferentes concentrações de FSH. Arq. Vet., v.23, p.172-177, 2007.

ROTH, Z.; ARAV, A.; BOR, A. et al. Improvement of quality of oocytes collected in the autumn by enhanced removal of impaired follicles from previously heat-stressed cows. Reproduction, v.122, p.737-744, 2001.

RUFINO JUNIOR, J.; OLIVEIRA, M.V.M.; CARVALHO, D.M.G. et al. Potencial produtivo de novilhas da raça "Pantaneira" alimentadas com fenos de baixa qualidade. Semina, v.35, Supl.1, p.2605-2616, 2014.

SILVA, I.J.O.; PANDORTH, H.; ACARARO JR., E. et al. Efeitos da climatização do curral de espera na produção de leite de vacas Holandesas. Rev. Bras. Zootec., v.31, p.2036-2042, 2002.

THOM, E.C. The discomfort indexIndex. Weatherwise, v.12, p.57-60, 1959.

TORRES-JÚNIOR, J.D.S.; DE FA PIRES, M.; DE SA, W.F. et al. Effect of maternal heat-stress on follicular growth and oocyte competence in Bos indicus cattle. Theriogenology, v.69, p.155-166, 2008.

VASCONCELOS, J.L.M.; DEMÉTRIO, D.G.B. Manejo reprodutivo de vacas sob estresse calórico. Rev. Bras. Zootec., v.40, p.396-401, 2011. 